Thorax (1964), 19, 316.

\title{
A method for the treatment of acute ventilatory failure
}

\author{
B R I A N A. E V A N S \\ From the Aylesbury and High Wycombe Area
}

Exacerbation of advanced chronic bronchitis produces an alteration in the arterial blood gases due to diffuse alveolar hypoventilation in lungs which are already the seat of considerable ventilationperfusion imbalance. In these circumstances the proportion of dead space ventilated per minute volume is increased, both in respect of the conducting airways and also as a result of the presence of inadequately perfused respiratory air spaces.

Treatment with oxygen and respiratory analeptics is the most frequently employed method of counteracting the resultant hypoxia but is limited in the degree to which it reverses carbon dioxide retention and facilitates the elimination of sputum (Hugh-Jones, 1958; Westlake and Campbell, 1959 ; Silipo, Hagedorn, Rosenstein, and Baum, 1961 ; Little, 1962 ; McNicol, Pride, Reynolds, and Semple, 1963 ; Canter, 1963). Failure of this regime can give rise to unnecessary delay in the performance of tracheostomy.

The method described offers an alternative form of treatment which is intended to provide continuous drainage of the bronchial tree from a supra-carinal level, together with functional annihilation of the anatomical dead space above this level. By comparison with a standard tracheostomy, it has the advantage of retaining the air-warming, humidifying, and filtering action of the upper respiratory tract, together with the cough reflex mechanism, of rapid and easy performance and closure, and of less demand on skilled nursing management. Moreover, standard techniques, such as the Venturi oxygen mask (Campbell, 1960a), remain applicable, and the rebreathing method for estimation of mixed venous $\mathrm{PCO}_{2}$ (Campbell and Howell, 1960) can be used if the catheter is disconnected.

\section{METHOD AND THEORY}

A Gibbon P.V.C. catheter of gauge 10-12 Charriere is introduced into the trachea through the cricothyroid membrane by a median stab laryngotomy so that it lies with its tip about 1 in. above the carina. A vacuum pump is connected to the other end of the catheter, and air is drawn through at a rate of about $101 . / \mathrm{min}$. (Fig. 1). An apparatus capable of maintaining a $\dot{\omega}$ vacuum of -10 in. $\mathrm{Hg}$ is adequate to aspirate the $\vec{\sigma}$ most viscid and tenacious secretions, whereas a 응 vacuum greater than 15 in. $\mathbf{H g}$ is liable to collapse the catheter. Mucopus within the bronchial tree is continually conveyed to the catchment area in the immediate vicinity of the catheter tip both by the cough mechanism, stimulated at first by its presence, and by the equally impaired ciliary action of the mucosa.

In addition to removing bronchial mucopus, continuous aspiration annihilates the dead space effect of the upper respiratory tract and trachea proximal to the catheter tip (volume approximately $50 \mathrm{ml}$.). Thus, during inspiration, air flow into the oro-nasal tracts is equal to the sum of the continuous catheter flow plus the inspiratory tidal volume; the comparatively low resistance of the upper airways presents a negligible increase in the muscular work required for inspiration since relatively low flow levels are involved for a large diameter airway, and under these conditions the constant pressure difference caused by the steady catheter flow will be minimal. During the expiratory phase, evacuation of air is continuously aided by the catheter suction such that flow reversal, i.e., outflow, into the proximal (upper) airway occurs only when the expira- 8 tory flow rate exceeds that in the catheter. As long $₹$ as obstruction of the distal airways continues to limit $o$ the rate of expiration, flow reversal will be small or even absent, and expired air which does pass the $\frac{7}{0}$ catheter tip will be drawn back and carried away in the interval before the succeeding inspiration. When $N$ this begins, the proximal airway will be filled by mostly atmospheric air because the concentration of $N$ carbon dioxide passing the catheter tip during expira- N tion increases steadily from a virtual zero to approach 0 a plateau maximum representative of alveolar $\mathrm{CO}_{2}$ tensions, and the latter high concentrations will be drawn away first as the flow rate falls towards the of end of expiration.

Flow reversal is measured with a Wright respirometer (Wright, 1959) fitted to a face mask or air-tight $\frac{0}{\mathbb{D}}$ mouth-piece (with nose clip) to record expiration. An $\stackrel{\square}{\square}$

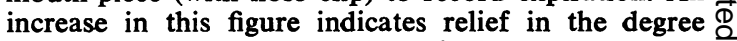
of distal airways obstruction if the catheter flow remains constant. This can be checked indirectly by reversing the instrument to record inflow, and noting 8 
FIG. 1. Diagrammatic representation of the principle described, one purpose of which is to remove expired air from the airway proximal to the catheter tip (illustrated by the broken arrow).

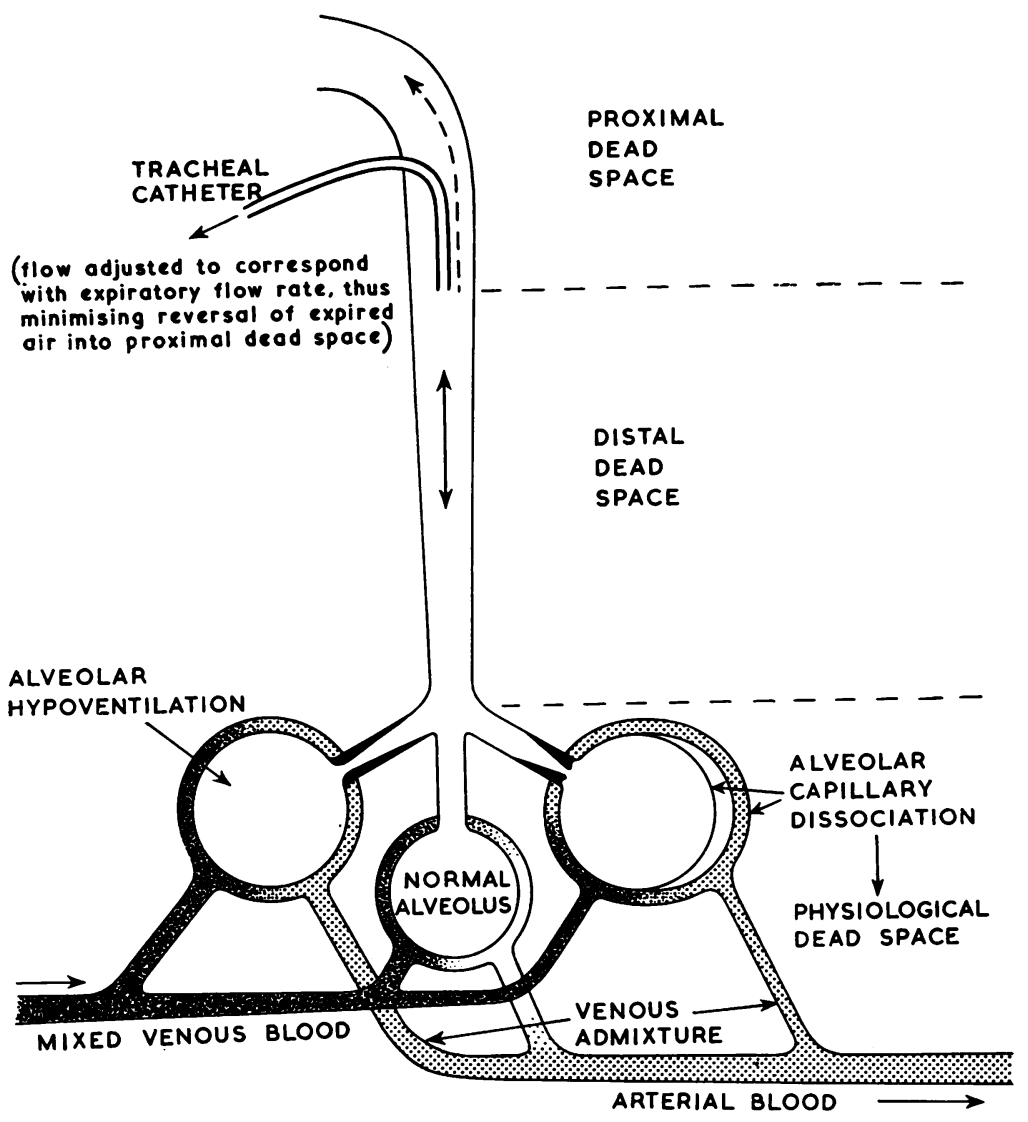

the difference between this measurement and expiratory flow reversal, which represents air extracted by the catheter if the lung gas exchange ratio is regarded as unity. As the respirometer records one rectified component of an alternating flow, this method of derivation should result in cancellation of any constant error inherent in the instrument, such as that due to slip.

Treatment is directed at restitution of the patient's metabolic equilibrium, with return of the blood gases to their previous levels and the consequent reversal of narcosis, together with adequate spontaneous expectoration. When this is achieved and improvement ceases, suction is discontinued for increasing intervals, the nature and volume of sputum are observed, and successive blood $\mathrm{PCO}_{2}$ estimations are performed in order to ensure satisfactory resolution of the disorder or the early recognition of relapse.

\section{EXPERIMENTAL EVIDENCE}

Several series of tests were conducted in an attempt to demonstrate the efficacy of this method in annihilating dead space. A normal subject (vital capacity 5 litres) breathed through a wide bore rubber tube (volume $350 \mathrm{ml}$.), normally used with a spirometer, which constituted an artificially extended dead space with a total volume more than three times normal. A 12 FG Gibbon catheter was fitted to draw air from the mouth-piece of this tube, which was intended to simulate the trachea and upper airway in a patient with the catheter inserted via the cricothyroid membrane, as previously described. Under these conditions no pressure variation was shown in the vicinity of the catheter tip either with or without suction; forced hyperventilation was necessary before any significant reading of the order of $1 \mathrm{~cm}$. $\mathrm{H}_{2} \mathrm{O}$ could be obtained.

In the first set of measurements (Table I), the percentage carbon dioxide content of expired air was recorded after intervals of 30,60 , and 90 seconds rebreathing, which began at an end-tidal point and ended with the final expiration diverted from the mouth-piece to fill a rubber bag at a time closest to that stated. Samples, taken in random 
TA B LE I

EFFECT OF AN ADDITIONAL DEAD SPACE IN PROMOTING $\mathrm{CO}_{2}$ RETENTION, AND ITS CJUNTERACTION BY CON-

\begin{tabular}{|c|c|c|c|}
\hline \multirow[b]{2}{*}{$\begin{array}{c}\text { Time } \\
\text { Interval } \\
\text { (sec.) }\end{array}$} & \multicolumn{3}{|c|}{ Percentage Carbon Dioxide Content } \\
\hline & $\begin{array}{c}\text { Normal } \\
\text { (control) }\end{array}$ & $\begin{array}{c}\text { Additional } \\
\text { Dead Space } \\
(350 \mathrm{ml} .)\end{array}$ & $\begin{array}{l}\text { Additional } \\
\text { Dead Space } \\
\text { with Air } \\
\text { Extraction } \\
\text { (approx. 10 } 1 . \\
\text { min.) }\end{array}$ \\
\hline $\begin{array}{l}60 \\
90\end{array}$ & $\begin{array}{l}\text { Mean } 5 \cdot 3 \\
\text { Range } 5 \cdot 1-5 \cdot 4 \\
\text { S.D. } 0 \cdot 12\end{array}$ & $\begin{array}{l}\text { Mean } 6 \cdot 1 \\
\text { Range } 5 \cdot 85-6 \cdot 45 \\
\text { S.D. 0.18 } \\
\text { Mean } 6 \cdot 0 \\
\text { Mean } 5 \cdot 75\end{array}$ & $\begin{array}{l}\text { Mean } 5 \cdot 4 \\
\text { Range } 5 \cdot 1-5 \cdot 55 \\
\text { S.D. } 0 \cdot 17 \\
\text { Mean } 5 \cdot 35 \\
\text { Mean } 5 \cdot 3\end{array}$ \\
\hline
\end{tabular}

sequence with the subject at rest, were analysed with a Campbell modified Haldane apparatus (Campbell, 1960b) and consisted of tidal air plus a reasonably constant fraction of the expiratory reserve volume contained in a 2 -litre rebreathing bag. The figures quoted are the arithmetic mean of approximately six results in each case.

The second series of measurements (Table II) concerned the relation between vacuum pressure and the catheter extraction rate, and the effect of these on air flow both in and out of the extended dead space, the latter being an indication of the extent to which expiratory flow reversal is prevented, and, thus, the dead space effect abolished. Readings were taken with the resting subject respiring through the $350 \mathrm{ml}$. tube as soon as a steady minute volume had been established; vacuum pressure was then increased in steps of 1 in. $\mathrm{Hg}$, and an interval of about three minutes was allowed to elapse before the next minute inflow and outflow were successively recorded at the external orifice of the additional dead space.

T A B LE II

RELATION BETWEEN VACUUM PRESSURE, CATHETER AND DEAD SPACE AIR FLOWS, AND VENTILATION (With an additional $350 \mathrm{ml}$. breathing tube used to simulate the dead space effect of the upper respiratory airways in the technique described)

\begin{tabular}{|c|c|c|c|c|c|c|}
\hline \multirow[b]{2}{*}{$\begin{array}{l}\text { Vacuum } \\
\text { Pressure } \\
\text { (in. Hg) }\end{array}$} & \multicolumn{2}{|c|}{$\begin{array}{l}\text { Dead Space Air } \\
\text { Flows }\end{array}$} & \multicolumn{2}{|c|}{$\begin{array}{c}\text { Catheter Flow } \\
\text { Rate }\end{array}$} & \multirow[b]{2}{*}{$\underset{\text { (1.) }}{\text { R.M.V. }}$} & \multirow[b]{2}{*}{$\begin{array}{c}\text { Respira- } \\
\text { tory } \\
\text { Rate }\end{array}$} \\
\hline & $\begin{array}{l}\text { Inflow } \\
\text { (1. / min.) }\end{array}$ & $\mid \begin{array}{c}\text { Out- } \\
\text { flow } \\
(1 . / \mathrm{min} .)\end{array}$ & $\begin{array}{c}\text { In- } \\
\text { direct } \\
\text { (1. min. })\end{array}$ & $\begin{array}{c}\text { Direct } \\
\text { (1. } \text { min.) }\end{array}$ & & \\
\hline $\begin{array}{r}0 \\
1 \\
2 \\
3 \\
4 \\
5 \\
6 \\
7 \\
8 \\
9 \\
10\end{array}$ & $\begin{array}{l}15.4 \\
15.3 \\
15.2 \\
15.8 \\
14.5 \\
14.1 \\
15.0 \\
15.5 \\
16.1 \\
16.4\end{array}$ & $\begin{array}{l}9.6 \\
7.0 \\
6.0 \\
5.7 \\
3.4 \\
2.2 \\
1.8 \\
1.3 \\
0.9 \\
0.4\end{array}$ & $\begin{array}{c}0 \\
5.8 \\
8 \cdot 3 \\
9 \cdot 2 \\
10 \cdot 1 \\
11 \cdot 1 \\
11.9 \\
13 \cdot 2 \\
14 \cdot 2 \\
15 \cdot 2 \\
16.0\end{array}$ & \begin{tabular}{r}
\multicolumn{1}{c}{} \\
$4 \cdot 0$ \\
$6 \cdot 5$ \\
$8 \cdot 3$ \\
$9 \cdot 8$ \\
$11 \cdot 0$ \\
$12 \cdot 1$ \\
$13 \cdot 3$ \\
$14 \cdot 1$ \\
14.9 \\
15.7
\end{tabular} & $\begin{array}{r}16.6 \\
14.9 \\
13.3 \\
11.9 \\
10.5 \\
10.0 \\
9.2 \\
8.6 \\
8.2 \\
7.9 \\
7.6\end{array}$ & $\begin{array}{c}15 \\
14-15 \\
14 \\
14 \\
13-14 \\
13 \\
13 \\
13 \\
12-13 \\
12 \\
12\end{array}$ \\
\hline
\end{tabular}

Normal R.M.V. (without additional dead space) 7.6 litres Range $6 \cdot 9-8 \cdot 6$; S.D. $0 \cdot 53$.
Finally, the inspiratory minute volume wase recorded over the same range of suction pressureso (Table II) with the respirometer this time inter-음 posed between the additional dead space and the $\overline{\frac{D}{5}}$ subject; a steady state was again awaited before systematic raising of the vacuum pressure at inter-p vening periods of three minutes.

Figure 2 shows the relation between negative. pressure and catheter flow measured directly, and $-\vec{\omega}$ that derived by plotting dead space outflow in aos
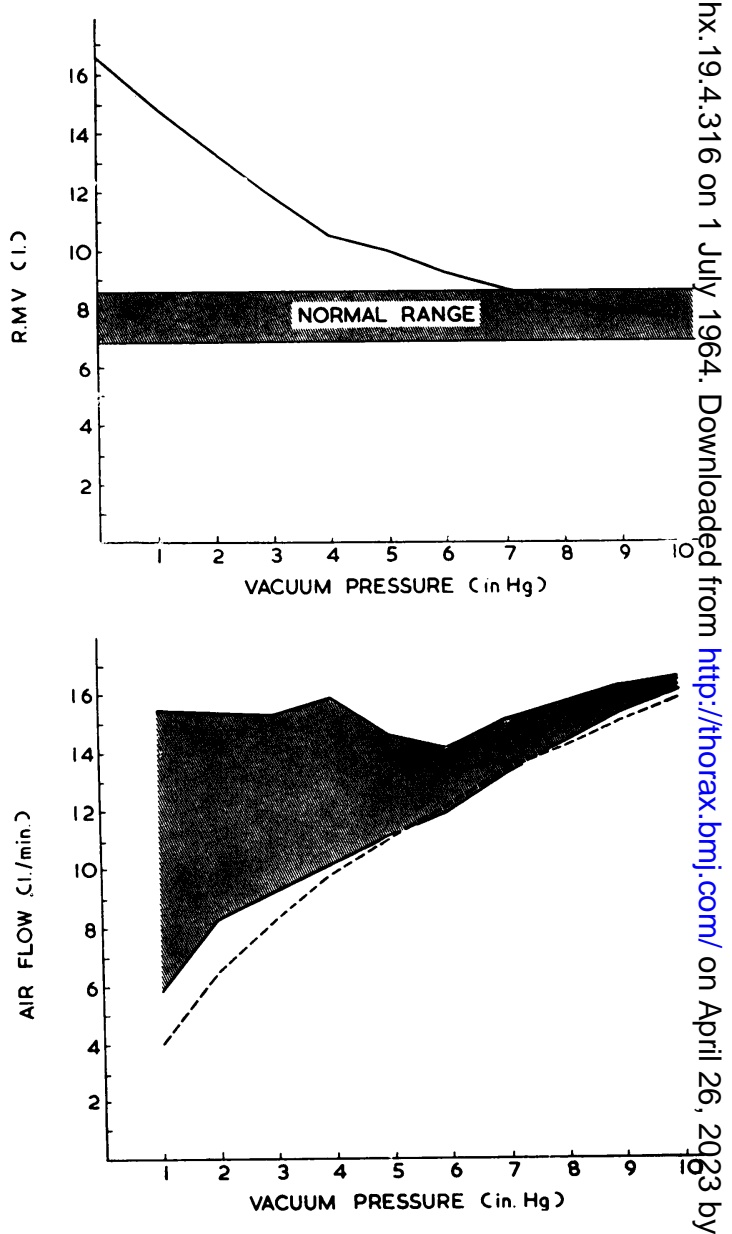

FIG. 2. (Above): Progressive annihilation of the ded? space effect of an artificial airway extension, related increasing suction applied to a catheter at its distal end $:$; the subject's normal R.M.V. range is shaded. (Below) D Expiratory flow reversal into the extended airway measures as outflow at its external orifice and plotted from abo with inflow as the baseline. The lower limit provides an indirect indication of air flow through the catheter com pared with the steady flow record shown as an interrupted line. 
negative direction with inflow as the baseline. This illustrates the diminishing expiratory flow reversal associated with increasing suction, and affords a comparison between direct and indirect values for catheter extraction. The discrepancy at less than 10 litres $/ \mathrm{min}$. is probably explained by the steady flow calibration curve of the Wright respirometer, which shows that the instrument is correct at $16 \mathrm{litres} / \mathrm{min}$. but $10 \%$ slow at 6 litres $/ \mathrm{min}$., and up to $20 \%$ slow at 5 litres $/ \mathrm{min}$. ; in fact, it slips up to 2 litres/min. throughout its range.

Restoration of the normal R.M.V. is correspondingly depicted (Fig. 2).

\section{DISCUSSION}

These results illustrate that the percentage carbon dioxide content in a fixed volume of expired air, and thus also presumably in alveolar air and arterial blood, is rapidly raised by a substantial increase in dead space, and that this is succeeded by a compensatory rise in minute volume; failure of carbon dioxide excretion occasioned by diminished alveolar ventilation consequent upon enlargement of the dead space continues until the tidal volume rises by an equivalent amount, i.e., $350 \mathrm{ml}$., or respiratory frequency is appropriately increased to maintain the previous alveolar ventilation. The practical consequence of rising volume and frequency of tidal ventilation is reflected by the progressive fall in percentage carbon dioxide after longer breathing periods. In contrast with control readings, however, the percentage expired carbon dioxide is virtually unchanged when air is continuously extracted from the distal end of the additional dead space at a rate of approximately 10 litres/min.

Low extraction rates claim but a small proportion of expired air so that most of the tidal volume enters the proximal dead space, and sufficient has to be exhaled right through it to enable the subsequent inspiration of enough atmospheric air to maintain alveolar ventilation. However, a fraction of the expired air filling this dead space at the onset of inspiration will be taken by the catheter, so that less than the full volume is actually rebreathed. This effect is inversely proportional to the inspiratory flow rate, or, more directly, proportional to the time taken for inhalation of the proximal dead space volume, and also, of course, to the catheter extraction rate; it applies until expiratory flow reversal is prevented by increasing suction, and expired air can no longer be drawn from the airway proximal to the catheter tip at any time during the respiratory cycle.

\section{Actual dead space $=$}

$$
\text { Airway volume }- \text { Catheter flow rate } \times \begin{gathered}
\text { Duration of dead } \\
\text { space inhalation }
\end{gathered}
$$

As suction is increased, so a diminishing amount of expired air enters the proximal dead space, until its presence as such becomes annihilated at the stage when air extraction reaches the maximum expiratory flow rate and the airway remains filled by atmospheric air at end-expiration. Nevertheless, the dead space continues to be reduced progressively as soon as less than its own volume is expired into the proximal airway. In the foregoing experiment, this expiratory benefit commences at vacuum pressures in excess of 4 to $5 \mathrm{in} . \mathrm{Hg}$; at 4 in. $\mathrm{Hg}$ or less the additional tube is filled by tidal air. Accordingly, the final equation becomes

$$
\begin{aligned}
& \begin{array}{l}
\text { Actual dead space }= \\
\begin{array}{c}
\text { Expiratory flow } \\
\text { reversal }
\end{array}
\end{array} \text { - Catheter flow rate } \times \begin{array}{c}
\text { Duration of dead } \\
\text { space inhalation }
\end{array} \\
& \text { Respiratory frequency }
\end{aligned}
$$

but is obviously invalid when the result is greater than the airway volume.

Dead space is effectively annihilated at a stage before the complete prevention of expiratory flow reversal, because when these phenomena become superimposed expired air is removed from the proximal airway in the course of gradual phase reversal before end-expiration.

PROCEDURE A male Gibbon catheter (12 FG), together with its plastic stylet, is cut off squarely to a length of 4 to $5 \mathrm{in}$. beyond the retaining flaps in which a hole has been punched at both ends.

The introducer ${ }^{1}$ (Fig. 3) consists of a $4 \mathrm{~mm}$. diameter hollow trocar, curved through 90 degrees at a radius of 1 in., its cannula open longitudinally along the internal border to allow lateral removal of the catheter. Trocar and cannula are formed to an oblique point on the external circumference, which must be maintained in a high degree of sharpness.

Intubation of the trachea is greatly facilitated by correct positioning of the patient in the best attainable attitude of head and neck extension compatible with the patient's condition. After the anterior cervical skin surface has been sterilized, the cricoid cartilage is located by palpation and a $\frac{1}{2}$ in. diameter bleb raised by intradermal injection of local anaesthetic in the midline directly above it, and infiltration is continued down to the cricothyroid membrane, which is then penetrated to confirm satisfactory siting before the slow instillation of 1-2 ml. of surface anaesthetic (4\% lignocaine or $5 \%$ cocaine hydrochloride) warmed to

1 The tracheal catheter introducer was made by the G.U. Manufacturing Co., Ltd., 28a, 33/34 Devonshire Street, London, W.1. 

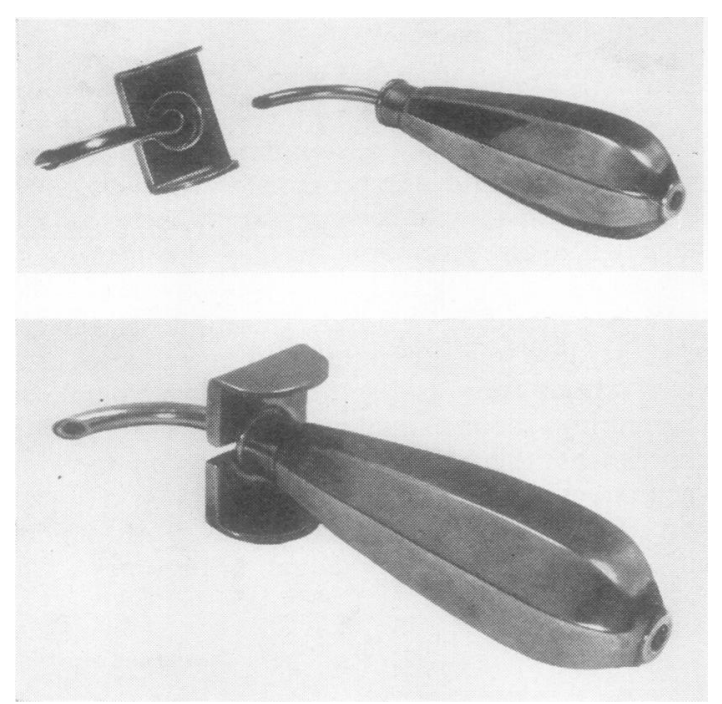

FIG. 3. The catheter introducer consists of a curved trocar and longitudinally split cannula, which can be slipped off the catheter sideways as soon as it has been passed into the trachea.

body temperature. A stab incision with a pointed scalpel blade ('Paragon' no. 11) is then made in the centre of the anaesthetic bleb, also down to the membrane, in order to provide a track for subsequent insertion of the cannula. This is begun with the instrument held horizontally over the manubrium, the cannula point in the previously made incision, and the larynx controlled with the other hand; introduction is effected by combined pressure at the point of entry and elevation of the handle to pass through 90 degrees about this point until the cannula hilt lies flush with the skin surface. Correct entry is sensed by the diminished resistance which is felt when the cricothyroid membrane is penetrated, but it can be confirmed by inserting a Luer-fitting syringe into the end of the trocar handle and aspirating air. When the trocar has been withdrawn, a Gibbon catheter, cut short as previously described, is fed into the trachea up to the cannula hilt, the cannula is carefully withdrawn, and the catheter, manipulated free from it, is pushed fully home so that its flaps can be secured around the neck with tape tied through the previously punched holes. Finally, the plastic stylet is removed, the catheter is connected to a vacuum pump, and the vacuum is increased to $4-5 \mathrm{in} . \mathrm{Hg}$ or that required to abolish outflow at the nose and mouth.

In the event of blockage, vacuum pressure will rise, ultimately to the limit of the machine, but in practice the catheter will usually clear spontaneously if the vacuum is bled off to remain below $10 \mathrm{in}$. $\mathrm{Hg}$, sufficient to restore patency of the lumen, and if this fails it is best cleared with an air-filled syringe applied at the adaptor union.

PRELIMINARY EXPERIENCE Several points have emerged in the preliminary use of this technique, and a number of theoretical problems have been clarified.

In contrast to the complications that led to rejection of the more readily performed laryngotomy in favour of tracheotomy for by-pass of the upper respiratory passages, toleration of the $\dot{\omega}$ narrow P.V.C. tube has presented no real diffi- $\vec{\sigma}$ culties. Post-mortem examination of one patient $ᄋ$ who died with the catheter in situ and of two who died respectively two days and 10 days after its removal showed no evidence of subglottic inflammation, ulceration, or cicatrization. In the latter case, withdrawal after three weeks' continuous $\stackrel{\curvearrowright}{\oplus}$ location had been followed by rapid closure and healing by first intention in a man of 85 years. If replacement becomes necessary for any reason, it should be undertaken immediately after removal and without the aid of the introducer in order to avoid enlargement of the puncture with its attendant risk of surgical emphysema, and a fresh catheter complete with stylet should be used.

Continuous influx of air via the oropharynx tends to dry the mucosa so that frequent mouth swabbing is required in a deeply narcotized patient, and, later, periodic drinks or mouthwashes are necessary. While the suction is in operation, phonation is, of course, to some extent impaired, but the tube can be pinched off when the patient wants to speak.

The first patient on whom catheterization of the trachea was carried out in this way was a $\frac{\text { s }}{5}$ small, kyphotic, comatose 63-year-old woman, $\rightarrow$ whose best recorded one-second forced expiratory volume was 0.3 litre.

Post-operatively, a young man in coma with gross restriction of ventilation due to abdominal 0 trauma and sepsis developed laryngeal stridor $\omega$ after one hour's continuous suction; this was immediately relieved by occluding the tube but 0 returned as soon as the vacuum was released $\Phi$ again. Direct laryngoscopy showed blood clot on + the vocal cords, suggesting that this represented a ${ }^{\circ}$ laryngeal guarding reflex intended to prevent its $\underset{\mathbb{D}}{\stackrel{\circ}{0}}$ entry into the trachea. Should such a complication arise and prove impossible to relieve, little if any- $\stackrel{\square}{\Omega}$ thing has been lost as the catheter can be removed 0 simply at any time, and may prove useful during the introduction of a tracheostomy tube. 


\section{SUMMARY}

A technique is described for the treatment of profound or rapidly progressive carbon dioxide narcosis and hypoxaemia due to acute ventilatory failure. It consists of trans-cricoid intubation of the trachea with a narrow bore P.V.C. catheter, which serves both to aspirate bronchial secretions from a supra-carinal catchment area and to provide a continuous influx of atmospheric air to this area, thus annihilating the dead space effect of the airway proximal to it. The method is fully compatible with standard forms of medical treatment and may well obviate the need for some of them.

I wish to record my thanks to Dr. A. Stephen Hall, on whose patients this work was carried out, and to Dr. W. T. Bermingham, whose joint encouragement at the outset was invaluable, and also my sincere respect for those patients who were involved.

\section{REFERENCES}

Campbell, E. J. M. (1960a). A method of controlled oxygen administration which reduces the risk of carbon-dioxide retention. Lancet, $i, 12$.

(1960b). Simplification of Haldane's apparatus for measuring $\mathrm{CO}_{2}$ concentration in respired gases in clinical practice. Brit. med. J., $i, 457$.

and Howell, J. B. L. (1960). Simple rapid methods of estimating arterial and mixed venous $\mathrm{pCO}_{2}$ Ibid., $i, 458$.

Canter, H. G. (1963). Comparative study of three respiratory stimulants in chronic obstructive emphysema. Amer. Rev. resp. Dis., $87,830$.

Hugh-Jones, P. (1958). Oligopnoea. Proc. roy. soc. Med., 51, 104.

Little, G. M. (1962). Use of amiphenazole in respiratory failure. Brit. med. J., $i, 223$.

McNicol, M. W., Pride, N. B., Reynolds, E. O. R., and Semple, S. J. G. (1963). Nikethamide for severe $\mathrm{CO}_{2}$ retention in exacerbations of chronic bronchitis. Ibid., $i, 646$.

Silipo, S., Hagedorn, C., Rosenstein, I. N., and Baum, G. L. (1961). Experiences with ethamivan, a new respiratory stimulant and analeptic agent. A preliminary report. J. Amer. med. Ass., 177, 378.

Westlake, E. K., and Campbell, E. J. M. (1959). Effects of aminophylline, nikethamide, and sodium salicylate in respiratory failure. Brit. med. J., $i, 274$.

Wright, B. M. (1959). In Symposium on Pulmonary Ventilation, Leeds, 1958, edited by R. P. Harbord, and R. Woolmer. Sherratt, Altrincham. 